\title{
Academies Release Long-Awaited MS\&E Study Report
}

\section{Background}

The National Research Council's (NRC) newly issued study report, Materials Science and Engineering for the 1990's: Maintaining Competitiveness in the Age of Materials, is the response of the National Academy of Sciences (NAS) and the National Academy of Engineering (NAE) to recommendations from the U.S. Congress, federal agencies, and the scientific community that the materials field needed a comprehensive assessment. These recommendations culminated in a forum at the Academies' Washington, DC facility in the spring of 1985 held under the joint auspices of the Solid State Sciences Committee (SSSC) of NAS and the National Materials Advisory Board (NMAB) of NAE, which considered the efficacy of such a study. By summer 1986, a Committee on Materials Science and Engineering was formed, agency funding acquired, and the organization and pursuit of the MS\&E Study begun. These early events were reported in previous issues of the MRS BULLETIN, ${ }^{1}$ where the topical division of labor into five study panels and the panel membership rosters can be found.

Early in the process, in response to the Study's call for input from the materials science community, ${ }^{2}$ MRS held a forum at its 1986 Fall Meeting in Boston. ${ }^{3}$ This produced a book, Communications on the Materials Science and Engineering Study, which provided input to the Study from MRS members and meeting attendees.

By 1987, anecdotal summaries of the panels' observations were being presented at meetings of professional societies, including MRS. ${ }^{4}$

The Study then dropped from public view for well over a year, now surfacing in the form of a 279-page volume released to the public on October 1, 1989. Also available is a booklet with only the report's summary for those not inclined to wade through 279 pages. Perusal of the full volume, however, reveals that the writing and organization is concise and lucid, that findings, recommendations and background data are clear and, in many cases, compelling. A researcher, research manager, or research funder will be well served by

1. MRS Bulletin 10 (3) (1985) p. 35; 11 (1) (1986) p. 63; 11 (3) (1986) p. 34; 11 (6) (1986) p. 41

2. MRS Bulletin 11 (3) (1986) p. 37; 12 (1) (1987) p. 75.

3. MRS Bulletin 11 (3) (1986) p. 30; 11 (6) (1986) p. 40; 12 (2) (1987) p. 79

4. MRS Bulletin 11 (6) (1986) p. 42; 12 (3) (1987) p. 32; 14 (2) (1989) p. 51 reading this tome from cover to cover.

An early goal enunciated by the Study Chairs, Praveen Chaudhari of IBM Corporation and Merton Flemings of Massachusetts Institute of Technology, was to produce a report of manageable size so as not to deter its reading and negate its impact. The present work is indeed far less intimidating than its 1975 predecessor, the five-volume COSMAT study, Materials and Man's Needs (National Academy Press, 1975).

\section{Organization and Scope}

The MS\&E Study report is not merely a concatenation of panel reports. The findings of the five panels have been combined and integrated to minimize duplication. Following a Summary, Conclusions, and Recommendations section, are the seven chapters comprising the body of the report:

1-What is Materials Science and Engineering?

2-Materials Science and Engineering and National Economic and Strategic Security.

3-Research Opportunities and Functional Roles of Materials.

4-Research Opportunities and the Elements of Materials Science and Engineering.

5-Manpower and Education in Materials Science and Engineering.

6-Resources for Research in Materials Science and Engineering.

7-Comparisons of Efforts in Materials Science and Engineering of Selected Nations.

Five appendices delve more deeply into "Issues in Materials Research." They contribute to greater understanding of the technical side of elements treated in the report and, in so doing, tend to add an extra underpinning to the report's central findings and conclusions, particularly with respect to Chapters 3 and 4 .

The following excerpt characterizes the scope of the contents beyond Chapter 1 :

"This report discusses the vital role that materials science and engineering plays in the development of technology. Chapter 2 summarizes the committee's findings about the impact of materials science and engineering on private and public sector activities that are crucial to U.S. economic and strategic well-being.

"Opportunities for research are discussed from two perspectives: Chapter 3 describes needs for new materials and for novel methods of processing in terms of the functional roles of materials; Chapter 4 describes research opportunities in the context of the four basic elements of materials science and engineering, thus emphasizing the intellectual coherence of the field while also stressing the essential connection between basic research and progress in developing materials.

"Educational challenges posed by the national need to encourage such progress and to ensure an adequate supply of welltrained materials researchers are considered in Chapter 5, which briefly assesses resources available for educating materials scientists and engineers at various levels of the U.S. educational system and also emphasizes the significance of the field's multidisciplinary aspect.

"Chapter 6 presents the committee's findings about funding and facilities currently available-as well as those needed in the future-to support the research efforts of materials scientists and engineers who work at the perennially shifting boundary between gathering knowledge and applying it.

"Finally, to examine from a broader perspective its assessment that materials science and engineering is vital to the future development of U.S. technology, the committee also examined how a number of nations view materials science and engineering and its role in their development. The international perspective is presented in Chapter 7. The committee is convinced that its findings and recommendations, if implemented, will strengthen the field of materials science and engineering and, in so doing, will contribute immeasurably and in unanticipated ways to meeting U.S. needs for economic and strategic security as well as the future needs of mankind."

\section{Recurring Themes}

Not withstanding the extreme diversity of the field and the breadth of coverage to which no short article could do justice, a few themes do permeate the Study's work. One stems from the NRC's principal goal for the Study-to present "a unified view of recent progress and new directions in materials science and engineering." The Committee on MS\&E states on page one that the "unified view" translated into "developing a concensus.... in the very diverse [MS\&E] community [which] was taken no less seriously than...the scientific and engineering assessment."

The report advocates treating the field of MS\&E as a coherent whole. It recommends several forms of cooperation and 
coordination among industrial, federal and university sectors. Recognizing that the field draws together many scientific and engineering disciplines, the report recommends that professional societies associated with MS\&E establish mechanisms for cooperative action to advance the field as a whole, and claims that an "emerging sense of unity" already exists.

A second recurring theme is the importance of the neglected fourth element of MS\&E-synthesis and processing. MS\&E is described as consisting of four interconnected aspects-structure/composition, properties, performance, and synthesis/ processing-represented graphically as vertices of the MS\&E tetrahedron (a symbol which may well become the logo of the field).

While the COSMAT study thoroughly articulated the intimate relationship along the structure-property-performance chain, the new Study emphasizes synthesis/ processing as a fully coordinate component in MS\&E-and one needing attention now to promote further rapid technological advance. The advances to date are very nicely summarized in Chapter 1 , where a litany of astounding improvements over time in properties and, thus, measures of materials performance are illustrated.

A third pervasive theme reflects the contention that U.S. industrial competitiveness in today's global markets relies ever more heavily on our ability to move basic research through the innovation process to the factory floor and that (1) the U.S. is not performing adequately, and (2) MS\&E is critically positioned for and of vital relevance to improving the U.S. posture in this regard.

\section{Some Individual Views}

Before the MS\&E Study's unveiling at a joint SSSC/NMAB forum, held September 26-27, 1987 at the National Academy facilities in Washington, DC, the MRS BULLETIN talked to some of the report's architects. We offer their views directly.

\section{R. Glen Kepler}

Alluding to all three of the above themes, R. Glen Kepler (Sandia National Laboratories), vice-chairman of the Panel on Exploitation of Materials Science and Technology for the National Welfare, commented, "This report makes it very clear that the field of materials science and engineering has a tremendous impact on our national competitiveness and on our national security. For that reason I believe the report will have an impact on national policy. Federal support for materials science and engi- neering has shown a downward trend over the past decade and I hope that it will help reverse that trend.

"The Japanese have shown that tremendous benefits accrue from both cooperation and some focusing of efforts at the national level. One of the committee's recommendations is that the government assume a more active role in bringing together the various groups involved in materials science and engineering and in enhancing communication, interaction and coordination among the many sectors affected by materials science and engineering. We have already seen some motion in this direction and I hope that this report will accelerate it.

"The field of materials science and engineering has undergone and is undergoing dramatic changes. It wasn't too many years ago that we were primarily engaged in research into the properties of existing materials. Now we are devoting tremendous efforts to designing new materials for specific applications. As a result, a clear need for stronger effort in synthesis and processing has developed, and one of the committee's major recommendations is for increased funding in this area."

\section{Lyle H. Schwartz}

When asked to comment on his panel's results, Lyle $\mathrm{H}$. Schwartz (National Institute of Standards and Technology), chairman of the Panel on International Cooperation and Competition in Materials Science and Engineering, readily identified several important messages read by Panel 3 in its investigation of MS\&E in various countries:

"MS\&E," he said, "is one of the critical technologies identified by all technologically advanced countries for development as we enter the next century."

"Development of these critical technologies is being carried out as part of a government/industry partnership in all major nations but the U.S.," he continued. "Since our study was launched, a number of changes in the U.S. position have occurred, via initiatives from both administration and Congress, and others are pending; however, the role of the U.S. government as a partner with industry in the development and maintenance of technological leadership continues to evolve. At issue are questions of defense vs. commercial needs, direct funding of technology development vs. macroeconomic policy, use of national laboratories, basic vs. applied research funding by government, and many others, all of which will have profound effects on the future health of MS\&E in the U.S."

\section{Donald C. Shapero}

The MRS BULLETIN also approached Donald C. Shapero of the National Research Council. As staff director for the Board on Physics and Astronomy, he was charged with managing and coordinating the assembly of the final report-a long, arduous task from a study-wide vantage point. Asked for his thoughts on the Study's completion, he commented, "Materials science and engineering has roots that reach far back into the past. The Clovis point is among the most ancient tools whose manufacture depended on an intuitive understanding of materials properties. The history of materials abounds with unusual but effective empirical recipes; for example, the Romans lined the Nimes aqueduct with a concrete prepared from lime, pork fat, and the fluid that oozes from cut unripe figs. The aqueduct worked for four centuries.

"Empiricism continues to play an important role in materials engineering. But the many dimensions opened up by new materials have increased the volume of the parameter space that must be searched by empirical approaches to impractical levels in many cases. A fundamental approach is often required. And, the capabilities of modern instrumentation for characterization, theoretical approaches, and computer modeling and analysis methods have become powerful enough to attack complex materials problems.

"In every aspect, the scope of this field is vast. Many groups in the science and engineering communities are working together to solve materials problems. In so doing, they are using the complete arsenal of approaches and methods of engineering and science in a spirit of collaboration.

"To me, this breadth is the most striking aspect of the field. I saw this same spirit of cooperation in tackling a common problem in the conduct of the Materials Science and Engineering Study itself. Over 100 scientists and engineers worked on the Committee on Materials Science and Engineering and its panels. Often in the course of the Study they struggled to give expression to the sense of unity they all felt in the midst of the great diversity inherent in the field. I think they succeeded, and that success is embodied in the final report."

\section{James S. Langer}

James S. Langer (University of California/Santa Barbara) chaired the Panel on Research Opportunities and Needs in Materials Science and Engineering. We asked him to comment on the report's later-thanexpected appearance and on indications of considerable debate over a science versus 
engineering focus in putting the report together. His response: "Obviously, the report is late. It might have been much more useful had it been published a year or two ago, and many of us on the committee thought that was going to happen. For a variety of reasons, we didn't make it.

"The grumbles about balance between science and technology in the report make a much better topic for discussion. The original charge to the committee was, somehow, to 'unify the field.' But it's hard enough to 'define' materials science and engineering, let alone 'unify' it.

"My own opinion, after spending three years in this project, is that the strength of the field is not so much in its unity as in its diversity. Modern materials problems are becoming enormously complex, and they are going to require combinations of many different techniques and points of view for their solution, so I don't think we want to become anything like a unified discipline [emphasis added]

"What I believe the report is trying to emphasize in this regard is the growing interdependence between scientists and technologists in the materials area. We are trying to point out that materials technology increasingly needs scientific input, and that there are challenging fundamental questions lying not far beneath the surface of even the most nuts-and-bolts technological problems.

"Of course, the report was written by a committee, and it shifts back and forth between various scientific and technological points of view in a way that may be upsetting to people. I get rather grumbly myself when I think of all the literary and scientific gems produced by the Research Panel that were misplaced-or left out altogether-in the final version! But I'd like to think that the grumbles-at least some of themmean that we've done the job that we wanted to do."

Asked to expand on why he believes the claimed trend toward interdependence between materials scientists and technologists is a real and a new situation, Langer responded, "The main technical theme of the report is synthesis and processing, areas which obviously have a great deal to do with product design and manufacturing, and which have been left painfully undeveloped in the United States in recent years.

"What I heard over and over again, especially in discussions with our subpanel on industrial needs, was a conviction that the U.S. has its best chance of regaining leadership in these areas by taking advantage of its strengths in the uses of computers, that is, by developing quantitative, predictive approaches to the synthesis and processing of materials.

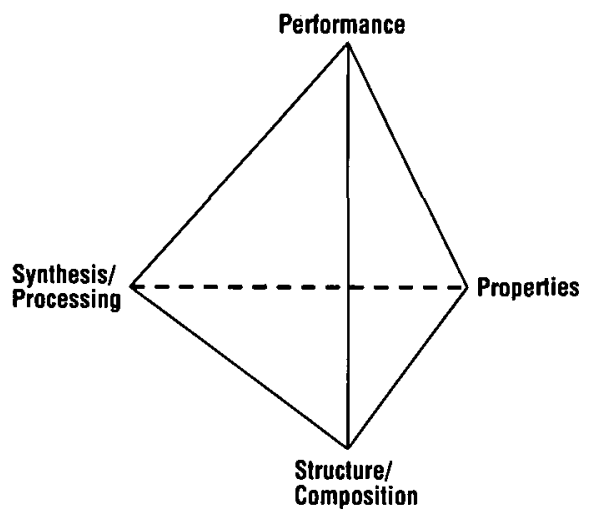

A tetrahedron illustrates the four interconnected aspects of materials science and engineering-structure/composition, properties, performance and symthesis/processing.

\section{National Labs and Tech Transfer}

Over the past five years, new legislation affecting technology transfer from national laboratories has been passed and some new methods for the transfer have been tried. We took the opportunity, therefore, to ask Lyle Schwartz what role he sees for these laboratories in the future development of MS\&E. "Speaking as an individual and for my laboratory at NIST," he said, "I think it is time for the national laboratories to go beyond the hackneyed phrase 'technology transfer' to a new era of 'joint technology development.' Technology transfer has the connotation of taking 'offthe-shelf' items, developed for some purpose related to the mission of the agency or laboratory and then reworking them so that someone in the industrial world can use them. We have all seen how frustrating and infrequently successful that process can be, although there are, of course, some notable success stories. By contrast, joint technology development implies that the laboratory and appropriately chosen industrial partners identify, in advance, a program of scientific and developmental work which takes advantage of the strengths of both institutions and leads to new technology. I think this strategy will be particularly appropriate in addressing the focus on processing of materials emphasized in the MSE report. Allow me to call attention to several current examples: the DOE/AISI steel program, the NIST Metal Powder Atomization Program, and the several developing consortia on high temperature superconductor applications. Our commercial competitors abroad have long ago learned how successful this use of national resources can be."

\section{Conclusions and Recommendations}

We enumerate many of the Study's conclusions and recommendations with the caveat that they are listed here out of context but presented to encourage you to review the Study itself.

MRS BULLETIN wishes to thank the National Research Council, Board on Physics and Astronomy, for providing an advance copy of the MS\&E Study report and also the individuals who discussed the Study with us as this article was in preparation.

\section{Conclusions of the MS\&E Study \\ - Role of Materials in Industry}

Materials science and engineering is crucial to the success of industries that are important to the strength of the U.S. economy and U.S. defense.

There is considerable overlap in the generic materials problems of the eight industries studied; solutions to many of these problems lie at the forefront of research in materials science and engineering.

The industry surveys revealed a serious weakness in the U.S. research effort in synthesis and processing of materials. There are opportunities for progress in areas ranging from the basic science of synthesis and processing to materials manufacturing that, if seized, will markedly increase U.S. competitiveness.

Increased emphasis on performance, especially as it is affected by processing, is also needed to improve U.S. industrial products for world markets.

Industry has the major responsibility for maintaining the competitiveness of its products and production operations. Greater emphasis on integration of materials science and engineering with the rest of their business operations is necessary if U.S. firms are to improve their competitive positions in domestic and international competition. Incentives for top-quality people to become involved in production will have to be introduced to achieve such an emphasis. Collaboration with research efforts in universities and government laboratories can enhance the effectiveness of R\&D programs too large for any one company The objective of all of these steps would be renewed emphasis on effective long-range $R \& D$ in industry.

\section{- Opportunities in Materials Science and Engineering}

The field of materials science and engineering is entering a period of unprecedented intellectual challenge and productivity.

Materials scientists and engineers have a 
growing ability to tailor materials from the atomic scale upwards to achieve desired functional properties.

In many industries, the span of time between insight and application is shrinking, and these processes are becoming increasingly interactive and iterative. Scientists and engineers must work together more closely in the concurrent development of total materials systems if industries depending on materials are to remain competitive.

\section{- Emerging Unity and Coherence of the Elements of Materials Science and Engineering}

Materials science and engineering is emerging as a coherent field.

An effective national materials science and engineering program requires healthy, balanced, and interactive efforts spanning basic science and technology, all materials classes, and the four elements of the field: properties, performance, structure and composition, and synthesis and processing

\section{- Instrumentation and Modeling}

Progress in the four elements of materials science and engineering can be enhanced through increased $R \& D$ on and use of advanced instrumentation ranging from the laboratory-bench scale to major national user facilities, and through increased emphasis on computer modeling and analysis of materials phenomena and properties based on the underlying physical and chemical principles.

\section{- Education}

The total number of degrees granted by materials-designated departments plus those granted in solid-state physics and chemistry and in polymer physics and chemistry in the field of materials science and engineering has remained essentially constant for more than 20 years, while opportunities in the field have expanded. If they are implemented, the initiatives recommended in this report will create an additional demand for highly qualified personnel in materials science and engineering.

There is a critical need for curriculum development and teaching materials for educational programs in materials science and engineering to reflect the broadening intellectual foundation of the field and the increased awareness of the importance of synthesis and processing.

\section{- Infrastructure and Mode of Research}

Small-scale research carried out by a principal investigator, sometimes with a small team, is cost-effective and is a major contributor to innovation. The United
States has excelled in this mode of research.

Large multidisciplinary teams are an effective mode for addressing industrial materials science and engineering problems.

At the national level, industry, university, and government laboratories have the technical strength to mount major efforts and to exploit breakthroughs in the field. All three have been found to be receptive to joint materials science and engineering programs that would be supportive of more rapid commercial development

\section{- Federal Support for Materials Science and Engineering}

There is a long-term downward trend in federal support for materials science and engineering that is significantly more pronounced for nondefense-related than for defense-related programs.

A strengthened national program in materials science and engineering is necessary to preserve the economic well-being and security of the nation.

\section{- Materials Science and Engineering in Selected Countries}

The governments of the major U.S. commercial trading partners and competitors, including Japan and West Germany, have targeted materials science and engineering as a growth area and, as a result, have developed strong competence in selected materials science and engineering areas.

These governments have taken a proactive role in deciding which areas of materials science and engineering will be emphasized on the basis of their contribution to enhancing industrial competitiveness.

The various governments use differing mechanisms for achieving national coordination of programs in materials science and engineering, with varying degrees of success.

\section{Recommendations of the MS\&E Study}

\section{- Strengthening Materials Science and Engineering}

The national program should include strong efforts in all four basic elements of materials science and engineeringsynthesis and processing, structure and composition, properties, and performance. The program should include work that explores the relationships among the four elements and that spans the range from basic science to engineering.

The elements of synthesis and processing as well as performance in relation to processing are currently relatively weak and should be emphasized within this national program.
The federal materials science and engineering program should be restored over the next several years to the levels that prevailed in previous decades in order to exploit the renewed opportunity to make accelerated progress.

New federal funds should be allocated for support of a national initiative in synthesis and processing. The initiative should provide support for facilities, education, and the development of research personnel. The strengths of universities, industry, and government should be brought into play, and the interactions of these three groups should be directed toward promoting the reduction of materials science and engineering results to commercial practice in the most effective possible manner.

Research on performance (including quality and reliability) should be increased, especially in relation to processing, but also in relation to the other elements of the field of materials science and engineering.

Increased emphasis should be given to computer-based analysis and modeling in research programs in materials science and engineering.

Government funding agencies should devote a portion of their materials science and engineering program budgets specifically to R\&D on and demonstration of new instruments for analysis and synthesis and processing of materials, including instruments that analyze processes in real time.

\section{- Maintaining and limproving the Infrastructure for Research in Materials Science and Engineering}

The U.S. national asset of excellence in the principal investigator mode of research should be preserved and strengthened in the field of materials science and engineering.

A balanced national program of resources, including major national user facilities for materials science and engineering, materials research laboratories, and other regional facilities, should continue to be developed.

Researchers who produce knowledge and those who apply it should continue to work together to identify the needs and opportunities in materials science and engineering, extending the work of this study through periodic reappraisals in selected areas. Such assessments should involve people from university, industry, and government laboratories.

Universities, industry, and government laboratories should develop joint programs in areas of national importance. Government laboratories should play a central role in this effort. 


\section{- Recognizing and Developing Unifying Trends in the Field of Materials Science and Engineering}

Universities, industry, government, and professional societies should strive to support and to accelerate the unifying trends that already exist in materials science and engineering.

Academic programs at the undergraduate level should be oriented to the elements of the field: synthesis and processing, structure and composition, properties, and performance.

At both the undergraduate and the graduate level, increased emphasis should be given to developing new courses and new textbooks that deal generically with all materials. The broadening intellectual foundation of the field and the importance of synthesis and processing should be reflected in these efforts.

Industry and universities should each take the initiative to work together in materials science and engineering with or without government as a partner.

The government should recognize the essential unity of materials science and engineering in its planning, funding, and coordinating activities.

The government should assume a more active role in bringing together the various groups involved in materials science and engineering and in enhancing communication, interaction, and coordination among the many sectors affected by materials science and engineering.

The committee endorses the goals adopted by the Congress in setting up the National Critical Materials Council, which should work with other agencies to ensure that the government carries out the facilitative functions as well as the more specific tasks identified above.

To accomplish the data collection and analysis that are critical to carrying out these tasks, the committee recommends that the National Critical Materials Council cooperate with other organizations such as the Office of Science and Technology Policy's Committee on Materials, the National Science Foundation, the Department of Energy, the National Institute of Standards and Technology, the National Research Council, and the professional societies.

E.N.K.

$$
\begin{aligned}
& \text { The strength of the field } \\
& \text { is not so much in its } \\
& \text { unity as in its diversity. } \\
& \text { [J. Langer] }
\end{aligned}
$$

\section{MS\&E Study Critiqued at SSSC Forum}

The Solid State Sciences Committee and the National Materials Advisory Board met September 26 and 27 at the National Academy of Sciences in Washington, DC to unveil the completed report of the Committee on the Materials Science and Engineering Study. The forum was chaired by SSSC Chair B.R. Appleton of Oak Ridge National Laboratory.

The keynote speaker was Senator Pete Domenici (R-NM), who has been credited with several initiatives in Congress to enhance U.S. competitiveness by encouraging cooperation between government laboratories and industry. Domenici noted that the Study report points to the very university-industry-government laboratory link he espoused. He acknowledged that such links tend to be inhibited by U.S. culture, which is not so in other industrialized countries. "We can no longer rely on accidental interdisciplinary match-ups," Domenici said, pointing to the need for government to provide more incentive and coordination in this regard. He called on those present to help change the culture that has viewed industrial applications as a perversion of the basic research system or a diversion from excellence.

Study Co-chairs Praveen Chaudhari of IBM and Merton Flemings of Massachusetts Institute of Technology presented an overview of the report. Chaudhari emphasized the call for new dollars in synthesis and processing and called on policymakers in universities, industry, and government to use "unity of the field" in their planning and funding decisions. He noted that important areas requiring attention include computer modeling and instrumentation for MS\&E. Scientific instruments used for materials analysis now, he said, often become tools of tomorrow's technology, for example, the synchrotron for photolithography.

Flemings noted that the shift in the 1960s and 1970 s from the synthesis/processing component of MS\&E to structure and composition using newly developed analytical tools underlies the observed weakness we now suffer in synthesis and processing. Part of the remediation, he said, is the need now for new upper-level textbooks and curriculae emphasizing synthesis and processing.

Next on the agenda were responses to the Study from three government funding agencies.

Iran Thomas, director, Materials Sciences Division, Basic Energy Sciences, DOE, emphasized the distinction between the chemist's highly advanced ability to synthesize molecules of greater and greater complexity as opposed to the synthesis of a "kickable" material. It is in the latter context that synthesis is used in the Study report. Thomas pointed to a novel aspect of materials synthesis not covered in the Study but that will be the focus of a symposium at the upcoming MRS Fall Meeting-materials synthesis using biological processes. He also suggested the Study was somewhat weak in covering MS\&E for environmental concerns. However, he considered the report "in resonance with our goals, and the recommendations are sound."

Albert Schindler, director, Division of Materials Research, NSF, summarized his division's support for MS\&E as well as related support through engineering and educational divisions at NSF. As did Thomas, he noted that his agency supports several large user facilities for the field. He pointed to the need for much greater contributions to university instrumentation and the kind of interdisciplinary curriculum development which might be related to NSFsupported MRLs, MRGs, S\&TCs, and ERCs on campuses.

Benjamin Wilcox, assistant director for materials sciences, Defense Sciences Office, DARPA, summarized the advanced materials work carried out at DOD laboratories on such topics as combustion synthesis, explosives, high $T_{c}$ superconductors, diamond films, vapor-coated fibers in composites, Schottky barriers for imaging arrays, and titanium aluminides to name a few. He also described extramural programs. Wilcox characterized the Study report as "a milestone document, an excellent sequel to COSMAT."

Missing from the agencies' responses were any indications that adequate funds would be available to implement any of the Study's recommendations.

Details on research opportunities revealed in the report formed an hour-long presentation by James Langer, director, Institute for Theoretical Physics, University of California-Santa Barbara. Saying "the hunt-and-find era is over," Langer identified the unifying theme of the report as the need for quantitative (i.e., scientific) methods in design and control of synthesis and processing and prediction of performance. After enumerating many forefront accomplishments in MS\&E, Langer named MS\&E's diversity as the element on which it thrives but said the real challenge is to get people working together efficiently and effectively.

A panel discussion chaired by William $F$. 
Brinkman of AT\&T Bell Laboratories was intended to discuss implementation of the Study's R\&D recommendations. After comments on a few practical aspects, the panel spent most of their time discussing industry and education issues, topics of the next two panels. This reflected the difficulty apparent throughout the event of coming to grips with explicit implementation algorithms and action plans.

Responding somewhat to that missing aspect, NMAB Chairman James C. Williams of General Electric indicated that the NMAB will meet in April to attempt to form implementation plans. He asked the community to provide suggestions to either him or Appleton. Williams also praised the report, saying it "has done a good job of capturing the field, but ways must be found to promulgate the recommendations of the report....People in the field should consider it visible enough to provide them self-esteem."

George Parshall of DuPont summarized industry needs in MS\&E, again emphasizing synthesis and processing as a weak area.

In the panel discussion on industry needs, Peter Bridenbaugh of Alcoa recommended confining processing largely to industry, rather than depending on national laboratories. Dean Eastman of IBM, who chaired the discussion, commented, 'We'll be processing silicon forever," implying that greater sophistication will be involved. Eastman also predicted more optical components in computers than in telecommunications in 10 years.

Bridenbaugh expressed the "horrible feeling that we'll be preaching to ourselves-there are too many familiar faces [in the audience.]" Industry, he contended, needs the necessary databases to more intelligently manufacture materials, and federal laboratories should assume a dominant role in instrumentation and analysis to build those databases.

Peter Cannon, currently of Conductus Inc. and formerly of Rockwell, described the materials situation in the aerospace industry, focusing on the cost of materials in the finished product. He concluded that a need exists for specialty materials industries that can deal in relatively small quantities as a way to reduce the labor intensive portion of today's materials cost. He pointed to the clear dis-incentive to major metals producers to fill this role, as it would reduce their primary market.

The rest of the meeting focused on educational aspects of MS\&E at both graduate and undergraduate levels. Kathleen $C$. Taylor of General Motors emphasized that not enough students are in the pipeline to meet current needs. Several panelists dis- cussed mechanisms to raise awareness at the pre-college level to encourage enrollment in MS\&E degree programs. Many on the panel and in the audience questioned the value of bachelor's degrees in MS\&E, feeling that so diverse a field requires graduate education for mastery.

The discussion chaired by Mel Bernstein of Illinois Institute of Technology dealt with the mobility of student and faculty across department boundaries, appropriate organizational structure in MS\&E departments; difficulties of hiring faculty when multiple deans are involved, utility of regional centers for instrumentation, and difficulties in the traditional accreditation process.

From the audience, Jerome Cohen of Northwestern University helped close the forum on an upbeat note: When teaching younger students about MS\&E and its amazing accomplishments, he said, we mustn't forget to tell them about the people...presenting dry details from the MS\&E Study may be educational, but the human side is inspiring.

Reported by E.N. Kaufmann

\section{The Next Step}

In 1984, the MS\&E field was being chided to put its house in order. From Congressman Don Fuqua (then chairman of the House Committee on Science and Technology), from George Keyworth II (then Science Adviser to the President), and from Alvin Trivelpiece (then Director of DOE's Office of Energy Research), we heard the message: stop shooting yourselves in the foot and get together...find a way to lower the noise level of your internal debate and present government with a consensus view of what is important for the government to support and why.

The MS\&E Study is as much a reaction to these admonitions as to the real need for a complete assessment of the field in a form digestible by everyone who may influence the fortunes of MS\&E. The Study report doesn't provide a prioritized laundry list of specific programs to help government decide what to fund. Aside from specifically endorsing the priorities established in the earlier NRC study, Major Facilities for Materials Research and Related Disciplines (the "Seitz-Eastman Report," National Academy Press, 1984) [see the MRS BULLETIN 9, 1984 (5) p. 15 and (6) p. 27; 11, 1986, (1) p. 41], the current study points to broad technical areas and institutional relationships, which need support and improvement. The language used avoids overly technical or jargon-laden prose in favor of such earthy phrases as "modern synthesis and processing are neither string and sealing wax nor beaker and Ehrlenmeyer flask activities."

Now that the report is out, presumably its authors and contributors will pursue manifold avenues to bring its content and import to the attention of those who now occupy chairs such as those formerly held by Fuqua, Keyworth, and Trivelpiece.

Has the climate changed in the interim so as to affect this Study's usefulness and impact? When asked of his hopes for the report's political impact, Jim Langer replied, "I'm not very optimistic, especially after watching the NSF take what seems to be at the time we're talking yet another beating in Congress. We don't generate the big, visible projects that have political appeal and we shouldn't try to do so. On the other hand, if we're to have any chance of meeting the urgent challenges facing us, we need better support from the federal governmentnot just more money, but better understanding of the nature and importance of our field and of the modes of support essential for it."

Time will tell, but the report itself is a tour-de-force for MS\&E's future and is a must reference for any serious member of the materials community. Many organizations will undoubtedly be involved in promulgating the Study's message. For example, we have recently learned that the Federation of Materials Societies (FMS), whose members comprise a subset of the materials-related societies, will sponsor a workshop in the Washington, DC area to consider how to implement the Study's recommendations. The $M R S$ BULLETIN will follow these developments and will welcome readers' comments on the Study report.

E.N.K. 